\title{
Gestão da Inovação Tecnológica: Estudo de Cinco PMEs Portuguesas*
}

\author{
Ana María Barañano \\ Professora do Departamento de Gestão - Instituto Superior de Gestão (ISG) - Portugal \\ Pesquisadora - Centro de Investigação em Gestão (CIGEST) - Portugal
}

Recebido: 28/8/2003 Aprovado: 18/2/2005

\section{RESUMO}

O artigo apresenta os resultados de um aprofundado estudo exploratório sobre as práticas de gestão em cinco PMEs portuguesas inovadoras. O objectivo desta investigação consiste na identificação e avaliação dos factores organizacionais e de gestão que contribuem para o sucesso dos processos de inovação tecnológica. Os resultados obtidos podem também ajudar à identificação de práticas pouco adequadas ou de algumas lacunas em termos de gestão e, assim, das áreas a melhorar.

Existe uma série de diferentes factores (embora estreitamente inter-relacionados) que devem funcionar em conjunto para criar e reforçar o ambiente que facilita o sucesso da inovação tecnológica. $O$ estado da arte em relação a cada um destes factores, bem como a sua prática nas empresas estudadas, são apresentados no presente artigo.

$\mathrm{O}$ artigo conclui que há duas grandes barreiras à inovação nas empresas estudadas. Por um lado, detectamos a falta de recursos humanos qualificados. Esta lacuna não é preenchida pelo recurso ao conhecimento externo pois, por outro

* A autora agradece aos pareceristas anônimos os comentários sobre as versões anteriores este artigo. 
lado, há uma importante omissão na comunicação externa com os agentes geradores de conhecimento (universidades e institutos de investigação).

PALAVRAS-ChaVe | Inovação Organizacional; Fatores para o Sucesso da Inovação Tecnológica; Gestão da Inovação Tecnológica; Empresas Inovadoras

Códigos JEL | L2; L6; M0; M1

\section{ABSTRACT}

This article presents the results of an exploratory, in-depth research carried out to know the managerial practices of five Portuguese innovative SMEs. The purpose of this research was the identification and the assessment of the managerial and organizational factors which contribute to technological innovation success. The results obtained can be also useful to identify inadequate practices or even managerial shortcomings, and thus, areas of improvement.

There is a set of organisational and managerial factors which ought to work together to create and reinforce the kind of environment that enables technological innovation to succeed. The state-of-the-art regarding each of those factors, as well as their application to the firms under scrutiny, are presented in this article.

Two important barriers against innovation were found. On the one hand, a lack of qualified human resources was identified. On the other hand, such lack is not compensated by the establishment of external linkages with the sources of knowledge, such as universities and research centres.

KeYwORDS | Organizational Innovations; Determinants of Technological Innovation Success; Management of Technological Innovation; Innovative Companies

JEL-CODES $\quad$ L2; L6; M0; M1 


\section{Introdução}

O progresso tecnológico leva, através do aumento da produtividade/ competitividade das empresas, ao desenvolvimento económico que, por sua vez, eleva o nível de vida da população em geral. Contudo, os investimentos em tecnologia nem sempre atingem o nível esperado de produtividade/ competitividade e, portanto, de desenvolvimento económico e de melhoria da qualidade de vida. As empresas europeias protagonizam, em muitas ocasiões, esta situação. Por exemplo, em Portugal, no período 1990-1993, muitas empresas investiram montantes elevados em tecnologia. Agora, várias dessas empresas descobrem que os seus esforços não resultaram na melhoria esperada da sua produtividade/competitividade. Estudos realizados sugerem que esta incapacidade em atingir os aumentos de produtividade/competitividade esperados se deve, em grande parte, às dificuldades que muitas empresas portuguesas têm em fazer face aos aspectos intangíveis do progresso tecnológico, nomeadamente à gestão do processo de inovação (Corado Simões, 1997). Neste aspecto, as empresas estadunidenses têm tido historicamente um desempenho superior ao das europeias porque sempre foram muito mais rápidas na adopção de novas práticas de gestão tais como a divisionalização, o melhoramento contínuo ou a produção flexível, que acompanharam o desenvolvimento e a implementação de novas tecnologias (IMIT, 1996).

O sucesso da inovação tecnológica empresarial depende, em grande medida, de aspectos como a estrutura da força de trabalho, a estratégia, as alianças com outras empresas ou com universidades e, acima de tudo, a organização interna da empresa. O desenvolvimento de inovações tecnológicas está fortemente condicionado pela existência de um ambiente interno no qual as ideias criativas possam emergir e ser aplicadas com eficácia e os conhecimentos, quer tecnológicos, quer de gestão, possam ser acumulados.

O presente artigo apresenta os resultados do estudo de caso de cinco pequenas e médias empresas (PMEs) industriais (fornecedores especializados), portuguesas, inovadoras, e desenvolvendo as suas actividades nos sectores de fabrico de equipamento e maquinaria e de fabrico de maquinaria eléctrica e aparelhagem.

O objectivo desta investigação é uma primeira identificação das práticas de gestão habituais nas PMEs portuguesas inovadoras. Os resultados obtidos 
podem também ajudar à identificação de práticas pouco adequadas ou de algumas lacunas em termos de gestão e, assim, das áreas a melhorar.

$\mathrm{O}$ artigo estrutura-se da seguinte maneira: na segunda secção apresentamos a revisão de uma série de estudos empíricos relevantes na área de gestão da inovação por forma a identificar aspectos-chave para o sucesso. A terceira secção faz menção aos aspectos metodológicos da investigação. Na quarta secção apresentamos os principais resultados obtidos dos cinco estudos de caso. Finalmente, na quinta secção, apresentamos as conclusões.

\section{Práticas de gestão nas empresas inovadoras}

A abordagem teórica na qual se enquadra a presente investigação orbita à volta da teoria da empresa baseada nos recursos, iniciada por Wernerfelt (1984) e posteriormente desenvolvida por Grant (1996) e Spender (1996), até constituirem a teoria da empresa baseada no conhecimento. Mais tarde, esta teoria deu suporte à emergência de novos modelos de gestão e de medida do capital intelectual da firma (Kaplan \& Norton, 1996; Meritum, 2002; Sánchez et al., 2000). A teoria da empresa baseada no conhecimento tem reconhecido a importância do capital social (Nahapiet \& Ghoshal, 1998) dando muita ênfase às ligações externas como principal fonte de inovação e crescimento das empresas, nomeadamente das PMEs (Cooke \& Wills, 1999).

Existe ainda um corpo teórico que relaciona a gestão do conhecimento com a inovação e o crescimento. Há um número crescente de análises (Sirilli, 2003; Barañano, 2003; Tidd et al., 2001; Cobbenhagen, 2000, entre outros) que reconhecem a relevância da dimensão não-tecnológica para o sucesso dos processos de inovação tecnológica, o crescimento e a criação de valor. Mas, já desde meados do século XX, muitos foram os autores que tentaram identificar empiricamente os factores de gestão associados com o sucesso da inovação tecnológica (destacam-se, Carter \& Williams, 1957; Myers \& Marquis, 1969; Langrish et al., 1972; Hayvaert, 1973; Schock, 1974; Rothwell et al., 1974; Szakasits, 1974; Freeman, 1974, 1982; Utterback et al., 1975; Rothwell, 1976; Barañano, 1994, 2003; Corado Simões, 1997; Romijn \& Albadalejo, 2002; Galende \& de la Fuente, 2003). Um aspecto em que todos estes autores coincidem é que nenhum factor pode, por si só, determinar quer o sucesso quer o insucesso tecnológico. 
Nenhum elemento isolado tem possibilidade de ser eficaz e, portanto, nenhuma ferramenta ou técnica de gestão criará e sustentará sozinha um ambiente propício à inovação. A inovação é um complexo processo tecnológico, sociológico e económico, que envolve uma teia extremamente intrincada de interacçôes, tanto no interior da empresa como entre a empresa e as suas envolventes económica, técnica, concorrencial e social. Não se pode por isso esperar que o sucesso seja satisfatoriamente explicado em termos de apenas um ou dois factores. O que encontramos é um conjunto de diferentes factores (embora estreitamente inter-relacionados) que devem funcionar em conjunto para criar e reforçar o tipo de ambiente que facilita o sucesso da inovação tecnológica. Estes factores ou práticas de gestão podem agrupar-se em redor dos cinco eixos seguintes:

(i) criação e manutenção de canais de comunicação fluidos, quer internos, quer externos;

(ii) atenção aos clientes actuais e potenciais, envolvendo-os no processo de inovação;

(iii) apoio explícito da gestão cimeira à inovação tecnológica;

(iv) disponibilidade de recursos humanos altamente qualificados e presença na organização de indivíduos que apoiem os projectos de inovação tecnológica, especialmente nos momentos críticos;

(v) criação e manutenção de uma estrutura organizacional flexível.

\subsection{Canais de comunicação}

Ao ser a inovação tecnológica um processo complexo que exige uma rede de interacçóes, tanto no interior da empresa como entre a empresa e a sua envolvente (Caloghirou et al., 2004), não se pode esperar o sucesso dos processos de inovação sem a criação e a manutenção de fluidos canais de comunicação, quer internos quer externos.

O lançamento e a implementação de inovações dependem da combinação de diferentes tipos de conhecimentos, que habitualmente estão distribuídos entre as várias unidades organizacionais da empresa (Nieto, 2003). Em consequência, para as empresas terem sucesso nos seus projectos de inovação, necessitam da cooperação entre as áreas de investigação, desenvolvimento, produção, 
marketing e finanças, por forma a permitir a contínua partilha de dados, de informação e de conhecimentos (Carter \& Williams, 1957; Myers \& Marquis, 1969; Langrish et al., 1972; Hayvaert, 1973; Schock, 1974; Szakasits, 1974; Freeman, 1974, 1982; Rothwell, 1976; Barañano, 1994; Amabile, 1997; Tidd et al., 1997; Gurteen, 1998; McAdam \& McClelland, 2002).

Uma medida básica consiste na criação e manutenção de múltiplos canais de comunicação abertos, bem como em complementar os habituais canais verticais de comunicação, com canais de comunicação horizontais e diagonais que liguem indivíduos localizados em diferentes unidades organizacionais (p. ex., entre os gestores de diversos projectos ou departamentos).

A fluidez da comunicação interna e, acima de tudo, a integração de todas as actividades, que leva à concepção da empresa como um sistema, contribuirá para o lançamento de inovaçôes com sucesso, pois garante que todos os esforços apontem numa mesma direcção.

Este aspecto requer mais atenção à medida que aumenta a dimensão da empresa, pois quando a organização cresce torna-se mais complexa, e a comunicação interna, em geral, encontra obstáculos, convertendo-se assim num factor a cuidar.

Por outro lado, a comunicação que se estabelece com a envolvente não é menos importante (Veugelers \& Cassiman, 1999), pois garante que os esforços tecnológicos que se estão a realizar respondem a uma necessidade existente, ou pelo menos latente, no mercado, para além de ser uma importante fonte de ideias para desenvolvimentos futuros. Assim, pode ser extremamente frutífero estabelecer um estreito contacto com clientes, fornecedores e concorrentes. Além disso, por razôes de custo ou de complementaridade científico-tecnológica, muitas vezes a empresa ver-se-á obrigada a recorrer a fontes externas de conhecimentos (constituídas por entidades investigadoras com mais experiência e conhecimentos em relação a um tema específico, nomeadamente as instituições de ensino superior e os centros de investigação). Deve-se ainda considerar a hipótese de contactos com as agências, públicas ou privadas, de apoio à inovação (Assis, 1996; Romijn \& Albadalejo, 2002).

Finalmente, convém não esquecer que a comunicação e mesmo o estabelecimento de acordos de colaboração com agentes externos exige determinados requisitos internos, nomeadamente a pesquisa intencional de ideias potenciais, a vontade de partilhar conhecimentos, abertura para cooperar e um estilo de gestão aberto e 
descentralizado que permita que a comunicação se produza em todas as direcções possíveis e se sirva de múltiplos canais. Ou seja, uma eficaz comunicação interna é requisito indispensável para uma comunicação externa adequada e produtiva.

\subsection{Atenção ao cliente}

Uma das características do mundo dos negócios que mais incidência tem no sucesso da inovação tecnológica é a velocidade a que mudam as componentes do meio envolvente e, mais concretamente, as oportunidades de mercado e o desenvolvimento tecnológico.

As empresas inovadoras, conhecedoras dessa situação, mantêm uma forte orientação externa. O objectivo desta orientação é duplo: por um lado tentam identificar atempadamente a procura existente no mercado (mesmo antes de existir uma solução técnica para essa procura), bem como antecipar a procura futura; por outro, tentam acompanhar o desenvolvimento tecnológico, quer na sua área de actuação, quer em áreas afins e potencialmente convergentes. Isto é, as empresas inovadoras procuram uma aprendizagem interactiva com a sua envolvente (Lundvall, 1992; Galende \& de la Fuente, 2003).

Uma questão-chave é a determinação do momento exacto em que uma inovação deve ser lançada, para o qual a única via plausível é a manutenção de um contacto estreito com os clientes actuais e potenciais. Isto significa que estas empresas devem realizar um esforço substancial para envolver, educar e apoiar os utilizadores das suas inovações.

Práticas habituais nas empresas inovadoras de sucesso são (i) a análise das necessidades dos clientes actuais e potenciais antes de decidir a introdução de uma inovação, quer de produto, quer de serviço, quer de processo; (ii) o envolvimento dos clientes, actuais e potenciais, em todas as fases do processo de inovação (Corado Simões, 1997; Rothwell, 1976; Barañano, 1994); (iii) a introdução de modificações nos protótipos após os testes conduzidos pelos clientes; (iv) a introdução de modificações em produtos/serviços novos ou substancialmente melhorados depois do seu lançamento no mercado, após feedback dos utilizadores (Barlow \& Moller, 2004); (v) a preparação dos novos utilizadores para tirarem vantagem plena das inovações introduzidas (p. ex., através da organização de acções de formação) (Rothwell et al., 1974; Rothwell, 1976; Szakasits, 1974); 
e (vi) o fornecimento de serviços técnicos pós-venda eficientes e de confiança (Carter \& Williams, 1957; Rothwell, 1976).

Além disso, a boa atenção ao cliente deve ser apoiada numa cultura de qualidade total. Esta cultura envolve, entre outras coisas, uma elevada capacidade de design, processos de produção rápidos e o desempenho do trabalho de desenvolvimento de forma tão eficiente que se pode resolver qualquer emergência durante a produção-piloto (Rothwell et al., 1974; Szakasits, 1974; Rothwell, 1976; Corado Simóes, 1997; Tidd et al., 1997). Evitam-se assim ajustamentos inesperados já em plena fase de produção e eliminam-se muitos problemas técnicos antes do lançamento comercial.

\subsection{Apoio explícito da gestão cimeira à inovação tecnológica}

A inovação tecnológica envolve um importante esforço de aprendizagem e de mudança e é uma actividade arriscada e de elevados custos. Assim sendo, as empresas que desejem, ou não tenham mais remédio que inovar, precisam da energia suficiente para ultrapassar essas barreiras.

Os gestores cimeiros, geradores e transmissores dessa energia, devem incluir a inovação tecnológica na estratégia das suas empresas e criar e transmitir uma cultura da inovação que facilite a implementação dessa estratégia.

Uma estratégia activa de inovação, que procure reforçar a posição competitiva da empresa, deverá contemplar o lançamento ocasional de inovações radicais e a introdução contínua de inovações incrementais. Se tal não for possível, pelo menos deverá ser implementada uma estratégia "atenta" de inovação, em que a empresa não tomará iniciativas relevantes de lançamento de inovações radicais mas procurará, no entanto, acompanhar a evolução da concorrência e responder rapidamente às mudanças externas.

Quer uma estratégia “activa” de inovação quer uma estratégia "atenta” exigem um planeamento rigoroso: o programa de investigação e desenvolvimento deve ser periodicamente revisto, deve ser realizada uma análise técnico/económica das inovações, estas devem ser orçamentadas especificamente, quantificando as decisões de investimento, e deve ser levada a cabo uma previsão sistemática de vendas. Ou seja, a ideia de que a inovação surge do caos criativo raramente é sustentada pela realidade das empresas inovadoras. 
Os gestores capazes de definir e implementar estratégias de inovação devem ser capazes de adoptar uma visão de longo prazo, uma vez que os resultados das inovações, nomeadamente as de tipo radical, não surgirão rapidamente. Esta visão pode ser difícil de manter, especialmente quando exigências de resultados de curto prazo dos accionistas devem ser compatibilizadas com planos de desenvolvimento de tecnologia de longo prazo. Uma forma de lidar com este problema é focar-se não só nos retornos económicos do investimento mas também em outras considerações como penetração no mercado, crescimento futuro e benefícios estratégicos (Tidd et al., 1997).

Finalmente, nas empresas inovadoras iremos encontrar gestores que praticam uma gestão participativa, envolvendo todos os colaboradores no processo de inovação e estimulando a criatividade individual. Qualquer pessoa dentro da empresa pode ser criativa e possuir aptidóes para resolver problemas. $\mathrm{Na}$ medida em que cada colaborador conhece as suas tarefas melhor do que qualquer outra pessoa, ele ou ela são as pessoas mais indicadas para propor melhoramentos relacionados com as suas tarefas ou responsabilidades. Este facto prepara o terreno para a contínua introdução de inovações incrementais cuja soma pode ter um impacto considerável (Schock, 1974). É por isso que as empresas inovadoras utilizam mecanismos de envolvimento contínuo dos colaboradores. Ain$\mathrm{da}$, este envolvimento proporciona um auxiliar poderoso para facilitar o processo de adaptação organizacional, permitindo desta forma a ultrapassagem de obstáculos internos à inovação tais como diferentes formas de comportamento e estruturas organizacionais que reforçam o status quo. Consequentemente, nas empresas inovadoras iremos encontrar gestores que partilham problemas e ideias, recolhem sugestôes ouvindo os subordinados, decidem, explicam as decisões tomadas e facultam aos subordinados oportunidades de clarificação; ou mesmo gestores que responsabilizam os subordinados pela tomada de decisóes e pela sua implementação.

\subsection{Recursos humanos e indivíduos-chave}

$\mathrm{Na}$ era da tecnologia o factor humano tem-se revelado como uma das chaves para o sucesso empresarial. É um facto que a capacidade de uma empresa para tirar o máximo partido de um novo equipamento ou para criar 
novos produtos, serviços ou processos depende, em grande medida, do conhecimento e das aptidões daqueles que estão envolvidos na utilização e na produção dessas inovações. Por outras palavras, transformar a eficiência potencial oferecida por qualquer tecnologia em eficiência real está nas mãos dos recursos humanos empregues.

A disponibilidade de recursos humanos altamente qualificados é uma característica clara das empresas inovadoras de sucesso (Carter \& Williams, 1957; Langrish et al., 1972; Rothwell et al., 1974; Rothwell, 1976; Szakasits, 1974; Barañano, 1994; Freeman, 1974 e 1982; Galende \& Suarez 1998, 1999; Martínez-Ros \& Salas, 1999; Igel \& Islam, 2001; Galende \& de la Fuente, 2003). Estas empresas conseguem recrutar pessoal com conhecimentos especializados e com as aptidôes exigidas pelos processos de inovação tecnológica (nomeadamente, consciência da importância da qualidade, capacidade de comunicação, iniciativa e criatividade, capacidade para a resolução de problemas, capacidade de cooperação e trabalho em equipa e flexibilidade).

A rápida evolução das tecnologias existentes, o aparecimento contínuo de novas tecnologias e a convergência de domínios científicos e tecnológicos antes perfeitamente separados contribuem significativamente para a crescente complexidade do avanço tecnológico. Isto cria um imperativo para as empresas: captação e manutenção de colaboradores capazes de acompanhar este progresso tecnológico. Assim, as empresas inovadoras de sucesso distinguem-se pelas suas políticas de formação que fornecem aos colaboradores o conhecimento e as aptidões necessários para continuamente dar a melhor utilização a novos equipamentos e gerar inovações (Carter \& Williams, 1957; Schock, 1974).

Os programas de formação funcionam também como motivadores, pois os colaboradores qualificados dão valor à contínua aquisição de competências e conhecimentos e sentem-se valorizados pelas organizações que lhes fornecem os meios para essa formação contínua. Os programas de formação são também um meio de dar autonomia aos colaboradores, pois as pessoas qualificadas sentem-se equipadas para assumir mais responsabilidade e mostrar mais iniciativa. Finalmente, visto que os colaboradores qualificados se sentem menos ameaçados pela introdução de mudanças nas suas organizações, os programas de formação podem fazer parte de uma agenda alargada de inovações organizacionais (Tidd et al., 1997). 
Por outro lado, em qualquer empresa inovadora iremos encontrar uma série de indivíduos-chave que, localizados em posições de autoridade e/ou possuindo uma forma única de conhecimento (Langrish et al., 1972), farão contribuições críticas para o sucesso de um processo de inovação.

Segundo Tidd et al. (1997), um desses indivíduos é o sponsor ou pessoa com uma visão estratégica da inovação. É um indivíduo que angaria os recursos necessários para levar a cabo um projecto de inovação, ou que convence os membros mais hostis ou cépticos da empresa do interesse de levar para a frente um certo projecto de inovação. O sponsor tem poder e capacidade para influenciar os outros, sendo capaz de puxar os diferentes cordéis na empresa (muitas vezes a partir do seu lugar no conselho de administração). Não terá necessariamente um detalhado conhecimento técnico da inovação, mas é essencial que acredite no seu potencial estratégico para a empresa.

Um outro indivíduo-chave nas empresas inovadoras é o denominado inovador do negócio. Trata-se de um gestor, com uma visão comercial da inovação, que conhece profundamente o mercado e a perspectiva do utilizador. $\mathrm{O}$ inovador do negócio tem uma vontade clara de inovar, muita responsabilidade, autoridade, entusiasmo e envolvimento. Pode ser o director técnico, o director de investigação, o responsável pelo departamento de I\&DE, ou um gestor de projecto, mas pode ser também um director de vendas, ou o engenheiro principal. Ocasionalmente, especialmente em empresas mais pequenas, pode ser o gestor cimeiro.

Ainda iremos encontrar o líder do projecto, ou responsável por um projecto de inovação. É um indivíduo-chave pela sua visão tecnológica/científica e pela sua grande capacidade de coordenação, que está profundamente envolvido e tem autoridade para garantir que os objectivos definidos sejam atingidos.

O inventor é, segundo Tidd et al. (1997) e Rothwell et al. (1974), outro indivíduo-chave que, tendo uma ampla compreensão da tecnologia associada a uma inovação, bem como a inspiração para resolver muitos problemas de desenvolvimento, faz o maior contributo técnico relativamente ao desenvolvimento e/ou ao design de uma inovação.

Outro indivíduo que Tidd et al. (1997), Rothwell et al. (1974) e Rothwell (1976) consideram chave é o denominado campeão do produto. Trata-se de um indivíduo que, com o seu entusiasmo, promove activamente o progresso dos projectos de inovação, especialmente em períodos críticos ou em situações de crise. 
Tanto os inventores como os campeões de produto são particularmente eficazes quando a estrutura de gestão é descentralizada e quando o estilo de gestão é aberto e consultivo.

Finalmente, confirma-se a importância do gatekeeper. É o indivíduo que recolhe continuamente informação de diversas fontes externas e a distribui informalmente ao colega que maior partido tirará dela (Allen et al., 1971; Rothwell \& Robertson, 1973 e Lenox \& King, 2004).

Os papéis representados pelos diferentes indivíduos-chave acima descritos não serão necessariamente desempenhados por pessoas diferentes. Por exemplo, nas empresas mais pequenas poderemos encontrar um colaborador que é simultaneamente o inventor, o líder do projecto e o campeão do produto. Também será habitual verificar-se que o sponsor e o inovador do negócio são a mesma pessoa. Outro exemplo habitual, sobretudo em pequenas empresas de base tecnológica, será a concentração do inventor, do sponsor e do inovador do negócio na mesma pessoa, nomeadamente no fundador da empresa. Seja como for, as seis características destes indivíduos-chave deverão estar presentes nas empresas inovadoras. Isto é, qualquer projecto de inovação tecnológica requer que na empresa que o desenvolva se reúnam uma visão estratégica e comercial, conhecimentos tecnológicos e informação sobre os diferentes elementos do meio envolvente, capacidade de coordenação e muito entusiasmo.

\subsection{Estrutura organizacional}

A gestão das empresas inovadoras deve ser suportada por uma estrutura organizacional que torne viável o esforço de inovação. Caso contrário, a estrutura será uma barreira ou, pelo menos, atrasará qualquer iniciativa inovadora.

Quando se fala de uma organização inovadora, a palavra "organização" tem muito pouco a ver com estruturas formais (OECD, 1997), as tarefas, responsabilidades, funções, métodos e autoridade são constantemente redefinidos através da interacção entre os colaboradores que participam na execução conjunta de actividades ou na solução de problemas comuns. A cooperação é obtida por ajustamento mútuo, pelo que as interacções e a comunicação entre as pessoas tendem a identificar-se mais com consultas laterais do que com a tradicional autoridade vertical. 
$\mathrm{Na}$ procura da flexibilidade estrutural, tem surgido uma variedade de arranjos organizacionais (destacam-se Burns \& Stalker, 1994; Burns, 1990; Mintzberg, 1979, 1992; Womack et al., 1991; Castells, 1996; Ostroff, 1999). Entre eles deve-se salientar a denominada organização horizontal. Trata-se de uma rede dinâmica e planeada estrategicamente de unidades auto-programadas e auto-dirigidas baseadas na descentralização, participação e coordenação. Estas unidades tomam a forma de equipas multifuncionais e multidisciplinares, que são formadas com base na diversidade de conhecimentos, competências e comportamentos de indivíduos altamente qualificados e capazes de trabalhar em conjunto. As equipas oferecem mais do que a soma dos indivíduos isolados, em termos de fluência e geração de ideias e de soluções.

\section{Metodologia}

O presente estudo é de natureza exploratória. A sua metodologia apoiase em cinco estudos de caso, que envolveram visitas às empresas seleccionadas e entrevistas com questionário aos seus gestores cimeiros. Todas as visitas e as entrevistas foram realizadas durante o mês de maio de 2001. Por se tratar de um estudo onde apenas foi analisado um número muito reduzido de empresas, existem grandes limitações à generalização: nem todos os gestores de PMEs inovadoras de Portugal deverão, portanto, identificar-se com os resultados apresentados neste artigo.

\subsection{População e amostra}

A amostra de empresas foi seleccionada a partir de uma população composta das 474 PMEs portuguesas que reportaram actividades inovativas no Community Innovation Survey - CIS II (89 microempresas, 155 pequenas empresas e 230 empresas de média dimensão). A partir desta população, e por forma a encontrar um colectivo homogêneo, foram aplicados três critérios para a seleccção de uma amostra de empresas:

- sector de actividade - não sendo aconselhável misturar empresas industriais e de serviços, apenas as industriais foram seleccionadas para integrar a 
amostra. Além disso, seguindo a taxonomia de Tidd et al. (2001), apenas foram seleccionadas empresas que eram fornecedores especializados. Finalmente, foram escolhidos os três sectores de actividade com a maior proporção de empresas inovadoras: fabrico de equipamento e maquinaria (EU-NACE 29), fabrico de equipamento de escritório e computadores (EUNACE 30) e fabrico de maquinaria eléctrica e aparelhagem (EU-NACE 31); - dimensão da empresa - apenas foram consideradas as micro e as pequenas empresas, isto é, aquelas com um volume anual de vendas até 7 milhões de Euros, pois considerou-se que as empresas de média dimensão poderiam ter dinâmicas bem diferentes;

- área geográfica - por questões de conveniência, apenas as empresas da região de Lisboa e Vale do Tejo foram incluídas na amostra.

Após a aplicação destes critérios chegou-se a uma amostra de nove micro/ pequenas empresas industriais (fornecedores especializados) localizadas na região de Lisboa e Vale do Tejo, e desenvolvendo as suas actividades nos sectores de fabrico de equipamento e maquinaria, de fabrico de equipamento de escritório e computadores, e de fabrico de maquinaria eléctrica e aparelhagem. A distribuição da amostra segundo o sector de actividade e a dimensão da empresa é a apresentada na Tabela 1.

Das nove empresas da amostra apenas cinco concordaram em participar no estudo: duas no sector do fabrico de equipamento e maquinaria (EU-NACE 29) e três no sector do fabrico de maquinaria eléctrica e aparelhagem (EU-NACE 31).

\subsection{Caracterização geral da amostra}

Excepto para o caso de uma empresa, que foi criada em 1998, o resto da amostra é constituída por empresas numa fase de maturidade. Todas elas começaram as suas actividades como entidades privadas em que os proprietários eram também os gestores. Recentemente, duas destas empresas foram vendidas a grandes empresas, sendo agora subsidiárias destas. A amostra compreende três microempresas (com um volume anual de vendas até 1,5 milhão de euros) e duas pequenas empresas (vendas até 7 milhões de euros).

Em termos absolutos as despesas em investigação e desenvolvimento ex- 
TABELA 1

Amostra por sector de actividade e dimensão da empresa

\begin{tabular}{cccc}
\hline \multirow{2}{*}{ Sector actividade } & \multicolumn{2}{c}{ Dimensão da empresa } & Total \\
\hline EU-NACE 29 & 2 & Pequena & 5 \\
& $66,7 \%$ & $30,0 \%$ & $55,6 \%$ \\
& & & \\
EU-NACE 30 & & 2 & 2 \\
& & $33,3 \%$ & $22,2 \%$ \\
EU-NACE 31 & 1 & & 2 \\
& $33,3 \%$ & $16,7 \%$ & $22,2 \%$ \\
Total & 3 & & 9 \\
& $100,0 \%$ & $100,0 \%$ & $100,0 \%$ \\
\hline
\end{tabular}

Fonte: CIS II e elaboração própria.

perimental (I\&DE) são, no geral, bastante limitadas. Em 2000, duas empresas gastaram menos de $25.000 \bullet$, outras duas entre 25.000 e $100.000 \bullet$, e apenas uma gastou mais de $500.000 \bullet$. Porém, a maioria das empresas analisadas apresenta uma intensidade média ${ }^{1}$ ou alta $^{2}$ em I\&DE; podemos, portanto, afirmar que estamos a estudar empresas bastante empenhadas na produção de inovações tecnológicas.

\subsection{O questionário}

As entrevistas aos gestores foram realizadas com questionário por forma a uniformizar o tipo de dados/informação recolhidos e assim facilitar a análise posterior.

A estrutura do referido questionário resulta da organização dos aspectos identificados como sendo chave para o sucesso na análise comparativa dos estudos empíricos referidos na secção 2 do presente artigo. Assim, o questionário constava de seis secçôes e em cada uma delas foram tratados os aspectos consi-

\footnotetext{
1 A intensidade média em I\&DE corresponde a uma despesa em I\&DE entre $1 \%$ e $10 \%$ do volume de vendas.

2 A intensidade alta em I\&DE corresponde a uma despesa em I\&DE superior a $10 \%$ do volume de vendas.
} 
TABELA 2

Amostra por sector de actividade e dimensão da empresa

\begin{tabular}{|c|c|}
\hline Secção & Tópicos \\
\hline $\begin{array}{l}\text { Informação geral } \\
\text { da empresa }\end{array}$ & $\begin{array}{l}\text { Denominação social; localização (cidade); ano de fundação; actividade } \\
\text { principal; status da empresa; número de trabalhadores; volume de } \\
\text { vendas; despesas em I\&DE. }\end{array}$ \\
\hline \multicolumn{2}{|l|}{ Canais de comunicação } \\
\hline $\begin{array}{l}\text { Comunicação } \\
\text { interna }\end{array}$ & $\begin{array}{l}\text { Natureza da comunicação; frequência da comunicação; } \\
\text { unidades envolvidas. }\end{array}$ \\
\hline $\begin{array}{l}\text { Comunicação } \\
\text { externa }\end{array}$ & $\begin{array}{l}\text { Natureza da comunicação; frequência da comunicação; agentes } \\
\text { externos envolvidos; áreas funcionais da empresa envolvidas. }\end{array}$ \\
\hline Atenção ao cliente & $\begin{array}{l}\text { Análise das necessidades dos clientes antes da introdução de } \\
\text { uma inovação; envolvimento dos clientes no processo de inovação; } \\
\text { introdução de modificações nos protótipos após os testes conduzidos } \\
\text { pelos clientes; introdução de modificações nas inovações após } \\
\text { feedback dos utilizadores; investimento na formação dos clientes; } \\
\text { problemas pós-venda. }\end{array}$ \\
\hline $\begin{array}{l}\text { Apoio da gestão } \\
\text { de topo à inovação }\end{array}$ & $\begin{array}{l}\text { Estratégia da empresa; capacidades dos gestores para a gestão; } \\
\text { distribuição das funções de gestão pelos níveis hierárquicos; } \\
\text { áreas da empresa em que os gestores delegam mais frequentemente; } \\
\text { processo de tomada de decisões; grau de envolvimento } \\
\text { dos colaboradores na gestão; cultura corporativa. }\end{array}$ \\
\hline Recursos humanos & $\begin{array}{l}\text { Número de colaboradores; habilitações; formação contínua; selecção; } \\
\text { indivíduos-chave para a inovação. }\end{array}$ \\
\hline Estrutura organizacional & $\begin{array}{l}\text { Critérios de departamentação; número de níveis hierárquicos; } \\
\text { mecanismos de coordenação geral; mecanismos de coordenação } \\
\text { interdepartamental; melhoria contínua; inovações organizacionais. }\end{array}$ \\
\hline
\end{tabular}

Fonte: CIS II e elaboração própria.

derados relevantes segundo a evidência disponível. Um resumo do conteúdo do questionário encontra-se na Tabela 2.

\section{Práticas de gestão nas empresas inovadoras. Resultados obtidos}

\subsection{Canais de comunicação}

Segundo apontam os resultados obtidos (Tabela 3), a comunicação interna nas empresas analisadas é basicamente informal e contínua. De facto, na maior parte delas não existe nenhum tipo de comunicação formal. Na opinião dos gestores inquiridos, as empresas são tão pequenas que não há necessidade de 
TABELA 3

Comunicação interna: áreas funcionais envolvidas, natureza e frequência

\begin{tabular}{|c|c|c|c|c|c|}
\hline \multirow[t]{2}{*}{ Áreas Funcionais } & \multirow{2}{*}{$\begin{array}{l}\text { Natureza da } \\
\text { comunicação }\end{array}$} & \multicolumn{4}{|c|}{ Frequência da comunicação (em percentagem)* } \\
\hline & & Nunca & Raramente & Frequentemente & Continuamente \\
\hline \multirow[t]{2}{*}{ I\&DE e Compras } & Formal & 60 & - & - & 40 \\
\hline & Informal & - & - & 20 & 80 \\
\hline \multirow[t]{2}{*}{ I\&DE e Produção } & Formal & 60 & - & - & 40 \\
\hline & Informal & - & - & 20 & 80 \\
\hline \multirow[t]{2}{*}{ I\&DE e Marketing } & Formal & 60 & - & 20 & 20 \\
\hline & Informal & - & - & 60 & 40 \\
\hline \multirow[t]{2}{*}{ Compras e Produção } & Formal & 60 & 20 & - & 20 \\
\hline & Informal & 20 & - & 20 & 60 \\
\hline \multirow[t]{2}{*}{ Compras e Marketing } & Formal & 60 & - & - & 40 \\
\hline & Informal & - & - & 60 & 40 \\
\hline \multirow[t]{2}{*}{ Produção e Marketing } & Formal & 60 & - & - & 40 \\
\hline & Informal & - & - & 20 & 80 \\
\hline
\end{tabular}

* Computa-se a percentagem de empresas que estabelecem comunicação entre as diferentes áreas funcionais segundo os diferentes níveis de frequência.

Fonte: CIS II e elaboração própria.

canais de comunicação formalizados. Os departamentos que mais frequentemente se comunicam são I\&DE e compras, I\&DE e produção, e produção e marketing. Quando a empresa toma parte em projectos internacionais (como é o caso de uma das empresas analisadas) então é frequente também a comunicação com a área financeira.

A comunicação interna acontece em todas as direcçôes possíveis (Tabela 4). Contudo, a comunicação vertical é a mais frequente, seguida da comunicação horizontal. A comunicação diagonal acontece com frequência muito menor.

No que diz respeito à comunicação externa (Tabela 5), observa-se que quando as empresas analisadas estabelecem contactos com outras instituições, fazem-no principalmente com outras empresas (nomeadamente com clientes, mas também com fornecedores); sendo também mais frequente uma relação de natureza informal. A relação com os clientes, em todos os casos, é estabelecida 
TABELA 4

Comunicação interna: áreas funcionais envolvidas, natureza e frequência

\begin{tabular}{|c|c|c|c|c|c|}
\hline \multirow{2}{*}{$\begin{array}{l}\text { Tipos de } \\
\text { comunicação }\end{array}$} & \multirow{2}{*}{$\begin{array}{l}\text { Natureza da } \\
\text { comunicação }\end{array}$} & \multicolumn{4}{|c|}{ Frequência da comunicação (em percentagem)* } \\
\hline & & Nunca & Raramente & Frequentemente & Continuamente \\
\hline Comunicação & Formal & 60 & - & 20 & 20 \\
\hline vertical $^{1}$ & Informal & - & - & 20 & 80 \\
\hline Comunicação & Formal & 60 & - & 20 & 20 \\
\hline horizontal ${ }^{2}$ & Informal & - & - & 40 & 60 \\
\hline Comunicação & Formal & 60 & 20 & - & 20 \\
\hline diagonal $^{3}$ & Informal & - & 20 & 20 & 60 \\
\hline
\end{tabular}

* Computa-se a percentagem de empresas que estabelecem os diferentes tipos de comunicação segundo os diferentes níveis de frequência.

1 Pessoal em diferentes níveis hierárquicos dentro da mesma unidade organizacional (p. ex., empregados e seus supervisores, equipas de projecto e seus coordenadores).

2 Pessoal do mesmo nível hierárquico mas em diferentes unidades organizacionais (p. ex., gestores de diferentes projectos/ departamentos).

3 Pessoal em diferentes níveis hierárquicos e diferentes unidades organizacionais (p. ex., chefes de departamento e os gestores cimeiros).

Fonte: inquérito por questionário.

pelo departamento de marketing; enquanto a relação com os fornecedores, em $80 \%$ dos casos, é estabelecida pelo departamento de compras. A comunicação com rivais é praticamente inexistente. Como um dos gestores entrevistados explicou: "a relação com concorrentes portugueses é muito difícil porque não há confiança. $\mathrm{O}$ estabelecimento de relações com produtores é muito mais simples, estes têm outra cultura: a cultura da cooperação". A comunicação com universidades e centros de investigação (públicos e privados) é muito rara. De facto, apenas uma empresa reportou relações contínuas, quer formais, quer informais, com este tipo de instituições. A relação com estas instituições é estabelecida em $60 \%$ dos casos pelo departamento de I\&DE. A comunicação com as agências governamentais de apoio à inovação também é muito rara. Existe um certo cepticismo da parte de muitos dos gestores de empresas inovadoras no que respeita à utilidade dessas agências. Todas as empresas analisadas abordaram em pelo menos uma ocasião alguma destas agências, e todas manifestam uma muito má impressão. Alguns comentários relativos a estas agências 
TABELA 5

Comunicação externa: agentes, natureza e frequência

\begin{tabular}{|c|c|c|c|c|c|}
\hline \multirow{2}{*}{$\begin{array}{l}\text { Agentes } \\
\text { externos }\end{array}$} & \multirow{2}{*}{$\begin{array}{l}\text { Natureza da } \\
\text { comunicação }\end{array}$} & \multicolumn{4}{|c|}{ Frequência da comunicação (em percentagem)* } \\
\hline & & Nunca & Raramente & Frequentemente & Continuamente \\
\hline \multirow[t]{2}{*}{ Clientes } & Formal ( 1 ) & 25 & - & 50 & 25 \\
\hline & Informal ( 2 ) & - & - & 60 & 40 \\
\hline \multirow[t]{2}{*}{ Fornecedores } & Formal ( 1 ) & 20 & 20 & 20 & 40 \\
\hline & Informal ( 2 ) & - & - & 50 & 50 \\
\hline \multirow[t]{2}{*}{ Concorrentes } & Formal ( 1 ) & 60 & 20 & - & 20 \\
\hline & Informal ( 2 ) & & 25 & - & - \\
\hline \multirow[t]{2}{*}{ Universidades } & Formal ( 3 ) & $\begin{array}{l}40 \\
20\end{array}$ & 20 & 20 & 20 \\
\hline & Informal (4) & & 40 & 20 & 20 \\
\hline & & 40 & & & \\
\hline Centros de investigação & Formal (3) & 20 & 40 & - & 20 \\
\hline \multirow[t]{2}{*}{ (públicos/privados) } & Informal (2) & & 60 & - & 20 \\
\hline & Formal (5) & 75 & & 25 & \\
\hline governamentais & Informal (2) & 80 & - & 20 & _- \\
\hline
\end{tabular}

* Computa-se a percentagem de empresas que estabelecem comunicação com os diferentes agentes externos segundo os diferentes níveis de frequência.

( 1 ) Troca de informação, realização de testes, realização conjunta de actividades de I\&DE, estabelecimento de uma cooperação técnica a longo prazo.

( 2 ) Contactos pessoais.

( 3 ) Consultoria, contratação de investigação, utilização de equipamentos, intercâmbio temporário ou permanente de pessoal e obtenção ou atribuição de bolsas de estudo.

( 4 )Contactos pessoais, acções de formação e ensino e participação em conferências.

( 5 )Promoção e apoio da inovação, da colaboração inter-empresas, etc.

Fonte: inquérito por questionário.

são: "eles estão sentados nos seus luxuosos gabinetes, recebem-nos friamente e atiram-nos com uma pilha de formulários para preencher", "eles apenas estão interessados em receber empresas grandes e bem posicionadas", "só dão apoio às empresas ricas". Todos estes resultados confirmam os previamente obtidos pelo Community Innovation Survey (Conceição \& Ávila, 2001).

$\mathrm{Na}$ maior parte das vezes a comunicação externa é estabelecida a partir de contactos pessoais. Estes contactos poderão evoluir para esquemas mais formais, como interligação de actividades, ou mesmo alianças estratégicas. Aliás, a comunicação externa parece ser algo mais formalizada que a comunicação interna.

Em resumo, a comunicação, quer a nível interno, quer a nível externo, é basicamente de natureza informal. A comunicação interna acontece, com maior 
TABELA 6

Frequência da análise das necessidades dos clientes

\begin{tabular}{lcc}
\hline $\begin{array}{l}\text { Frequência } \\
\text { (em percentagem)* }\end{array}$ & Clientes actuais & Clientes potenciais \\
\hline Nunca & - & - \\
Raramente & - & 80 \\
Frequentemente & 80 & 80 \\
Sempre & 20 & - \\
\hline
\end{tabular}

* Computa-se a percentagem de empresas que analisa as necessidades dos seus clientes segundo os diferentes níveis de frequência.

Fonte: inquérito por questionário.

ou menor frequência, entre todas as áreas funcionais da empresa e em todas as direcções possíveis. A nível externo, a maioria dos contactos é estabelecida com os clientes e os fornecedores. As relações com instituições de investigação são muito escassas e com concorrentes e agências governamentais de apoio à inovação praticamente inexistentes.

\subsection{Atenção ao cliente}

A análise das necessidades dos clientes, quer actuais, quer potenciais, antes do lançamento de uma inovação tecnológica é prática frequente entre as empresas estudadas. Contudo, a análise das necessidades dos clientes actuais é mais frequente do que a dos clientes potenciais (Tabela 6).

Os resultados obtidos no inquérito (Tabela 7) indicam também que o envolvimento dos clientes no processo de inovação é menos frequente que a análise de necessidades. Por outro lado, o envolvimento dos clientes actuais também é mais frequente do que o de clientes potenciais, pois enquanto $60 \%$ das empresas analisadas envolvem, quer frequentemente, quer sempre, os seus clientes actuais nos seus processos de inovação, $40 \%$ das empresas nunca envolveram nos seus processos de inovação clientes potenciais.

O feedback dos clientes pode originar a introdução de modificações, quer nos protótipos após os testes levados a cabo pelos futuros utentes, quer nas 
TABELA 7

Frequência do envolvimento dos clientes no processo de inovação

\begin{tabular}{lcc}
\hline $\begin{array}{l}\text { Frequência } \\
(\text { em percentagem) }\end{array}$ & Clientes actuais & Clientes potenciais \\
\hline Nunca & - & 40 \\
Raramente & 40 & 20 \\
Frequentemente & 20 & 20 \\
Sempre & 40 & 20 \\
\hline
\end{tabular}

${ }^{*}$ Computa-se a percentagem de empresas que envolve os seus clientes segundo os diferentes níveis de frequência. Fonte: inquérito por questionário.

inovações após o seu lançamento no mercado. Segundo os resultados obtidos (Tabela 8), esta última situação parece ser mais frequente que a primeira, o que dá indícios de ineficiência nos custos, pois a modificação de protótipos é sempre mais barata e pode evitar a necessidade de modificar inovações já lançadas no mercado. Contudo, as empresas analisadas declararam que os seus produtos raramente experimentavam problemas técnicos pós-venda, embora seja frequente a necessidade de pequenos ajustamentos.

Por forma a maximizar o partido tirado pelos clientes do potencial de uma inovação, as empresas inovadoras devem investir tempo e recursos na educação/formação dos seus clientes. Este é o caso de $80 \%$ das empresas inquiridas.

Em resumo, a relação com os clientes é na maioria das vezes estabelecida no início do processo de inovação para a análise das suas necessidades, e após o lançamento das inovações para obter o seu feedback. Assim, o envolvimento dos clientes nas fases intermédias do processo de inovação é raro.

\subsection{Apoio explícito da gestão cimeira à inovação tecnológica}

Para conseguirmos avaliar o apoio dos gestores cimeiros à inovação, analisámos vários elementos, nomeadamente a estratégia da empresa, as capacidades dos gestores para a gestão, o grau de envolvimento dos colaboradores na gestão da empresa e a cultura corporativa. 
TABELA 8

Resultados do feedback dos clientes

\begin{tabular}{lcc}
\hline $\begin{array}{l}\text { Frequência } \\
\text { (em percentagem)* }\end{array}$ & $\begin{array}{c}\text { Modificações } \\
\text { nos protótipos }\end{array}$ & $\begin{array}{c}\text { Modificações } \\
\text { nas inovações }\end{array}$ \\
\hline Nunca & - & - \\
Raramente & 60 & 20 \\
Frequentemente & - & 40 \\
Sempre & 40 & 40 \\
\hline
\end{tabular}

* Computa-se a percentagem de empresas que introduz modificações segundo os diferentes níveis de frequência.

Fonte: inquérito por questionário.

Os resultados do inquérito realizado indicam que $80 \%$ das empresas analisadas mantêm uma estratégia activa de inovação. Trata-se, portanto, de empresas que têm uma política de lançamento contínuo de novos produtos e/ou de modernização dos processos utilizados; existe nelas uma grande utilização de ferramentas informáticas e procura-se recorrer a novas soluções organizacionais para reforçar a sua posição competitiva. São empresas que tentam levar à prática novos objectivos e novos projectos mesmo que estes envolvam riscos, embora os seus gestores façam um grande esforço para evitar situações de ruptura e para controlar o risco. Apenas encontrámos uma empresa com sérios problemas financeiros (o gestor e proprietário desta empresa estava a pensar vendê-la) e para a qual, no momento da realização do inquérito, a inovação tecnológica não formava já parte da sua estratégia.

Os gestores das empresas analisadas parecem estar bem equipados para a gestão dos processos de inovação. Os resultados do inquérito realizado (Tabela 9) indicam que as suas principais aptidões são a capacidade para utilizar informação, a capacidade para trabalhar em situações ambíguas e arriscadas, a cooperação, a liderança e a eficiência. Também caracteriza muitos dos gestores inquiridos a sua objectividade e confiança. Contudo, detectaram-se algumas áreas a melhorar, nomeadamente a capacidade para trabalhar em condiçôes de stress, a flexibilidade, a capacidade de ter uma visão sistémica dos problemas, e a comunicação verbal e escrita. ${ }^{3}$

\footnotetext{
3 A listagem das aptidões dos gestores foi obtida a partir dos resultados do projecto Priorities for Executive Development (PED) - programa Leonardo da Vinci - projecto nE97200453 EAIll 2.A. Para mais informação ver Rayney, B. et al. (2000).
} 
TABELA 9

Capacidades para a gestão

\begin{tabular}{lccc}
\hline $\begin{array}{l}\text { Capacidades } \\
\text { (em percentagem)* }\end{array}$ & Não & Indiferente & Sim \\
\hline Visão sistémica & 20 & - & 80 \\
Uso de informação & - & - & 100 \\
Stress & 40 & - & 60 \\
Ambiguidade & - & - & 100 \\
Objectividade & - & 20 & 80 \\
Cooperação & - & - & 100 \\
Flexibilidade & 40 & - & 60 \\
Liderança & - & - & 100 \\
Confiança & - & 20 & 80 \\
Comunicação Oral & 20 & - & 80 \\
Comunicação Escrita & 20 & 20 & 60 \\
Eficiência & - & - & 100 \\
\hline
\end{tabular}

* Computa-se a percentagem de empresas que envolve os seus clientes segundo os diferentes níveis de frequência.

Fonte: inquérito por questionário.

Observamos também que $80 \%$ dos gestores inquiridos concorda com a delegação de responsabilidades e autoridade. Esta delegação é maioritariamente selectiva orientando-se, em $60 \%$ dos casos, para o departamento de I\&DE, pois é o que habitualmente emprega o pessoal mais qualificado. Contudo, é interessante observar que embora a quase totalidade dos gestores inquiridos concordem com a delegação, esta não é uma prática habitual nas empresas analisadas. Assim, quando os gestores foram questionados sobre quais as responsabilidades mais frequentemente delegadas, comprovamos que nenhuma responsabilidade de gestão é delegada nos trabalhadores. Por outras palavras, existe delegação mas apenas entre os diferentes níveis de gestão.

A distribuição de funções entre os três níveis de gestão (Tabela 10) é a seguinte: as funções estratégicas relacionadas com o planeamento (nomeadamente a determinação do estado actual da organização, a previsão da situação futura da empresa, e o estabelecimento dos objectivos) são desempenhadas, na maioria dos casos, pelos gestores cimeiros, mas delegadas aos gestores intermé- 
dios em $40 \%$ dos casos. A análise da envolvente é uma função estratégica delegada em $60 \%$ dos casos nos gestores intermédios. Estas quatro funções estratégicas em nenhum caso foram delegadas nos supervisores. Os gestores intermédios são maioritariamente responsáveis pelo recrutamento e formação do pessoal bem como pela correcção dos desvios no desempenho. A definição das necessidades de recursos humanos, a monitorização dos resultados, a comunicação das mudanças aos subordinados e a revisão e o ajustamento em função dos resultados do controlo e das mudanças são funções realizadas em $40 \%$ dos casos pelos gestores cimeiros e em $40 \%$ pelos intermédios. As funções maioritariamente realizadas pelos gestores directos são de natureza operacional tais como a comunicação dos objectivos aos subordinados, a definição das acções a levar a cabo, a determinação dos recursos necessários e a sua distribuição entre os subordinados.

No que respeita ao processo de tomada de decisões diferenciaram-se quatro situações:

- processo de tomada de decisões centralizado e imposto - Os gestores cimeiros tomam as decisões e fornecem instruções concretas de actuação;

- processo de tomada de decisóes centralizado e liderado - Os gestores cimeiros tomam as decisões e delegam nos seus subordinados a implementação das decisões por eles tomadas;

- processo de tomada de decisóes centralizado com partilha de ideias - Os gestores cimeiros partilham os problemas e as ideias, recolhem sugestões dos seus subordinados e só depois decidem. Seguidamente, comunicam as decisões tomadas aos subordinados e estão disponíveis para fornecer os esclarecimentos necessários;

- processo de tomada de decisóes descentralizado - Os gestores cimeiros delegam a tomada e implementação de decisões, embora com algumas limitações (Corado Simões, 1997).

Os resultados obtidos no inquérito (Tabela 11) indicam que, enquanto em todas as empresas analisadas se pratica uma tomada de decisões centralizada mas com partilha de ideias, em vários casos existem também traços de processos de decisão mais ou menos centralizados. Não obstante, observe-se 
TABELA 10

Distribuição (em percentagem)* das funções de gestão pelos diferentes níveis de gestão

\begin{tabular}{|c|c|c|c|}
\hline \multirow[t]{2}{*}{ Funções de gestão } & \multicolumn{3}{|c|}{ Níveis de gestão } \\
\hline & Supervisores & Gestores intermédios & Gestores cimeiros \\
\hline \multicolumn{4}{|l|}{ Planejamento } \\
\hline $\begin{array}{l}\text { Determinar o estado presente } \\
\text { e futuro da empresa }\end{array}$ & - & 40 & 60 \\
\hline Previsão da situação futura da empresa & - & 40 & 60 \\
\hline Análise da envolvente & - & 60 & 40 \\
\hline Definição dos objectivos & - & 40 & 60 \\
\hline Comunicação dos objectivos aos subordinados & 80 & - & 20 \\
\hline Definição de aç̧ões e alocação de recursos & 60 & - & 40 \\
\hline \multicolumn{4}{|l|}{ Organização } \\
\hline $\begin{array}{l}\text { Distribuição das tarefas, responsabilidade } \\
\text { e autoridade e definiçẫo dos padrões } \\
\text { de desempenho }\end{array}$ & 60 & 20 & 20 \\
\hline \multicolumn{4}{|l|}{ Direcção } \\
\hline Definição das necessidades de recursos humanos & 20 & 40 & 40 \\
\hline Selecção e contratação de recursos humanos & - & 60 & 40 \\
\hline Treino e desenvolvimento dos recursos humanos & 20 & 60 & 20 \\
\hline \multicolumn{4}{|l|}{ Controlo } \\
\hline Definição de standards & 40 & 20 & 40 \\
\hline Monitorização dos resultados & 20 & 40 & 40 \\
\hline Implementação de acções correctivas & - & 60 & 40 \\
\hline Comunicação das mudanças aos subordinados & 20 & 40 & 40 \\
\hline $\begin{array}{l}\text { Revisão e ajustamento segundo os resultados } \\
\text { do controlo e das mudanças }\end{array}$ & 20 & 40 & 40 \\
\hline
\end{tabular}

* Computa-se a percentagem de empresas em que cada nível de gestão é responsável por cada função.

Fonte: inquérito por questionário.

que $60 \%$ dos gestores inquiridos se manifestaram totalmente em desacordo com a descentralização do processo de tomada de decisões. Este resultado é coerente com a falta de delegação para além dos níveis de gestão e é explicado, pelos próprios gestores inquiridos, pela falta de qualificações dos recursos humanos disponíveis. 
TABELA 11

Processo de tomada de decisões*

\begin{tabular}{lccc}
\hline Tipos de processos & Não & Indiferente & Sim \\
\hline Centralizado e imposto & 60 & - & 40 \\
Centralizado e liderado & 60 & 20 & 20 \\
Centralizado com partilha de ideias & - & - & 100 \\
Descentralizado & 60 & - & 40 \\
\end{tabular}

* Computa-se a percentagem de empresas que aplica cada tipo de processo de tomada de decisões.

Fonte: inquérito por questionário.

Observamos também que todas as empresas analisadas possuem mecanismos para detectar e resolver os problemas. Mais uma vez, estes mecanismos não estão formalizados, baseando-se na comunicação informal e no contacto directo entre os gestores e os colaboradores. Dada a pequena dimensão da maioria das empresas, estes mecanismos informais são suficientes para garantir a detecção e a solução atempada dos problemas.

Igualmente, todas as empresas inquiridas dispõem de mecanismos para a recolha de ideias. Mais uma vez, estes mecanismos são de natureza informal e, portanto, apoiam-se no contacto directo e na comunicação verbal. Contudo, os mecanismos para a recolha de ideias parecem estar mais formalizados que os utilizados para detectar e resolver problemas. O mecanismo formal mais frequentemente utilizado consiste na realização de reuniôes periódicas e na comunicação escrita entre as diferentes áreas funcionais.

Finalmente, para o estudo da cultura corporativa foi aplicada a classificação de Corado Simões (1997) que diferencia cinco tipos de cultura. Estes são os seguintes:

- Cultura Paternalista - A empresa assume uma certa responsabilidade pelo bem-estar do pessoal e a política de admissóes assenta mais no conhecimento e nas referências pessoais do que numa análise estrita de currículos; - Cultura Disjunctiva - Os gestores cimeiros centralizam a tomada de deci- 
sões, dão ordens e os colaboradores implementam-nas cumprindo as tarefas que lhes são atribuídas;

- Cultura Afirmativa - Estimula-se a afirmação pessoal, o profissionalismo, o dinamismo e a capacidade de resposta. Há uma preocupação de aproveitar ao máximo os recursos humanos existentes remunerando-os em conformidade. Os gestores cimeiros transmitem estes valores, sublinhando a importância do empenhamento e da capacidade de trabalho;

- Cultura Integrativa - Reforça-se a importância do trabalho em equipa e da comunhão de esforços para a realização dos objectivos organizacionais que são definidos pelos gestores cimeiros e comunicados a todos os colaboradores;

- Cultura Participativa - Aprofunda a cultura integrativa e esbate a dicotomia superior/subordinado. É fortemente estimulada a partilha de ideias e o recurso a formas articuladas de tomada de decisão e de definição da estratégia. Existe um sistema de valores que enfatiza o espírito de equipa e o trabalho em grupo. O relacionamento informal tem um papel decisivo na estruturação e na partilha de valores da organização.

Os resultados obtidos (Tabela 12) indicam que as empresas analisadas combinam traços de todas as culturas consideradas. A situação mais habitual é a de empresas que assumem responsabilidades pelo bem-estar do seu pessoal, a sua política de admissóes assenta mais no conhecimento e nas referências pessoais do que na análise do currículo, embora este também seja tido em conta. Esta situação explica-se facilmente pela própria cultura nacional caracterizada por um forte colectivismo (Hofstede, 1991). Contudo, estimula-se a afirmação pessoal, o profissionalismo, o dinamismo e a capacidade de resposta, há uma preocupação em aproveitar ao máximo o potencial dos recursos humanos, remunerando-os em conformidade, e a gestão de topo procura transmitir os valores de empenhamento e capacidade de trabalho. Em conclusão, existem valores ligados às culturas afirmativa, integrativa e participativa que são favoráveis à inovação mas também existem traços da cultura paternalista que podem ser uma barreira importante à inovação.

Em resumo, o apoio explícito da gestão cimeira à inovação tecnológica foi testado através da análise de vários elementos. A cultura corporativa mais fre- 
TABELA 12

Cultura corporativa*

\begin{tabular}{lccc}
\hline Tipos de cultura & Não & Indiferente & Sim \\
\hline Paternalista & 20 & - & 80 \\
Disjunctiva & 20 & - & 80 \\
Afirmativa & - & 20 & 80 \\
Integrativa & 20 & - & 80 \\
Participativa & 20 & - & 80 \\
& & & \\
\hline
\end{tabular}

* Computa-se a percentagem de empresas que possuem (ou não) traços das diferentes culturas corporativas.

Fonte: inquérito por questionário.

quente combina aspectos das culturas paternalista, afirmativa, integrativa e participativa. As relações informais desempenham um papel-chave na detecção e resolução de problemas e na recolha de ideias. Trata-se de empresas com uma "cultura de proximidade entre as pessoas" onde impera a comunicação informal e contínua. A gestão cimeira centraliza a tomada de decisões, embora exista uma importante partilha de ideias e os gestores se mostrem disponíveis para os esclarecimentos necessários em relação às decisōes tomadas. A delegação de funções de gestão nos empregados é nula, embora a maioria dos gestores inquiridos se declarem a seu favor. Finalmente, observamos que quase todas as empresas estudadas mantêm uma estratégia activa de inovação, apoiada por umas aptidōes para a gestão tais como a capacidade para utilizar informação, a capacidade para trabalhar em situações ambíguas e, portanto, arriscadas, a cooperação, a liderança e a eficiência.

\subsection{Recursos humanos e indivíduos-chave}

Em todas as empresas analisadas o grupo mais numeroso de trabalhadores é constituído pelos operacionais que, em média, representam 69\% do número total de empregados. A proporção média de indivíduos em posições de gestão é de $20 \%$ do total de trabalhadores. Entre eles, os gestores intermédios constituem o colectivo mais numeroso (Tabela 13). Este resultado indica que estamos 
TABELA 13

Distribuição dos recursos humanos*

\begin{tabular}{lcc}
\hline Colectivos & $N^{\circ}$ médio & $\%$ \\
\hline Operacionais & 31 & 68,9 \\
Pessoal administrativo & 5 & 11,1 \\
Supervisores & 2 & 4,4 \\
Gestores intermédios & 5 & 11,1 \\
Gestores cimeiros & 2 & 4,4 \\
Total & 45 & 99,9 \\
\hline
\end{tabular}

* Computa-se a percentagem de empresas que possuem (ou não) traços das diferentes culturas corporativas.

Fonte: inquérito por questionário.

perante estruturas organizacionais planas, onde os gestores intermédios absorvem muitas das responsabilidades dos gestores cimeiros e dos supervisores por forma a reduzir estes níveis de gestão.

Os resultados obtidos (Tabela 14) também indicam que o maior colectivo é constituído por colaboradores apenas habilitados com o ensino secundário. Em média, somente $29 \%$ dos recursos humanos têm algum grau académico de nível universitário (20\% possui um bacharelato ou licenciatura e $9 \%$ fez uma pós-graduação, um mestrado ou um doutoramento). O emprego de doutorados é praticamente inexistente, apesar do programa nacional expressamente criado para financiar a contratação destes pelas empresas. Estes resultados mostram claramente o baixo nível de qualificações dos recursos humanos. Facto que constitui uma grande barreira à inovação empresarial que, como já referimos, precisa de recursos humanos altamente qualificados. Isto pode ser, em parte, explicado pela prioridade concedida aos conhecimentos pessoais quando da selecção de recursos humanos. Aparentemente também existe uma barreira psicológica à contratação de pessoal altamente qualificado (nomeadamente de doutorados): poucos são os gestores que possuem um grau universitário superior à licenciatura, sendo o caso mais frequente o dos gestores sem nenhum grau universitário; assim, estes gestores sentem algum receio na contratação de pessoal mais qualificado que eles, pois consideram-no uma ameaça.

Em se tratando de empresas que actuam em sectores marcados pela incor- 
poração contínua de avanços científicos, pode-se aventar a hipótese de que um nível mais elevado de qualificação é dispensável para a competitividade das empresas.

Essa baixa qualificação dos recursos humanos não oferece perspectivas de melhoria, pois existe uma ausência quase total de acções de formação contínua. Os poucos cursos de formação reportados pelas empresas analisadas abordam temas técnicos e tecnológicos quando dirigidos exclusivamente pelos operacionais, mas os cursos assistidos por gestores, e por estes e empregados em conjunto, focam aspectos ligados à gestão. Os gestores frequentam maioritariamente cursos que abordam tópicos como a satisfação dos clientes e a gestão funcional. Os cursos destinados conjuntamente aos colectivos de empregados e de gestores abordam tópicos como cultura corporativa, flexibilidade organizacional e trabalho em equipa.

Finalmente, os indivíduos-chave mais frequentemente encontrados nas empresas analisadas são o sponsor, o inovador do negócio (ambos presentes em $80 \%$ das empresas analisadas) e o inventor (presente em 60\% dos casos). Isto quer dizer que a maioria das empresas combinam as abordagens estratégica, comercial e tecnológica do processo de inovação. $\mathrm{O}$ indivíduo-chave menos presente é o campeão de produto seguido pelo gatekeeper e pelo líder de projecto. O que significa que algumas das empresas analisadas podem carecer da coordenação, do entusiasmo e da informação externa exigida pelos processos de inovação.

Em resumo, encontramos na área de recursos humanos uma barreira à inovação: a falta de recursos humanos qualificados, agravada pela baixa participação em cursos de formação. Relativamente aos indivíduos-chave, a situação mais frequente é a cobinação da visão estratégica com a visão comercial e com a visão tecnológica do processo de inovação.

\subsection{Estrutura organizacional}

Todas as empresas estudadas mostram estruturas organizacionais com poucos níveis hierárquicos e combinando vários critérios de departamentalização (a situação mais frequente é a combinação do critério funcional com a segmentação por produtos ou por clientes). Apenas encontramos uma excepção: trata-se de 
TABELA 14

Habilitações dos recursos humanos

\begin{tabular}{lcc}
\hline Habilitações & $N^{\circ}$ médio & $\%$ \\
\hline Doutoramento & 1 & 2,2 \\
Mestrado & 2 & 4,4 \\
Pós-graduação & 1 & 2,2 \\
Licenciatura & 8 & 17,8 \\
Bacharelato & 1 & 2,2 \\
Ensino secundário & 18 & 40,0 \\
Ensino primário & 10 & 22,2 \\
Sem habilitações & 4 & 8,9 \\
Total & 45 & $99,9 *$ \\
\hline
\end{tabular}

* A soma não é $100 \%$ pelos erros de arredondamento.

Fonte: inquérito por questionário.

uma empresa que apresenta uma estrutura concebida para servir os clientes e onde as funçōes de marketing e qualidade ocupam posições prioritárias. A ideia por trás desta estrutura é uma pirâmide invertida baseada no conceito de cliente interno.

Para garantir a coordenação geral das diferentes funções, todas as empresas analisadas empregam de maneira frequente ou contínua o contacto directo e informal e a supervisão; os sistemas (informatizados) de informação e, para as tarefas mais repetitivas, a estandardização dos processos de trabalho são utilizados continuamente por $80 \%$ das empresas. A padronização dos resultados e dos conhecimentos (mecanismos habituais nas empresas inovadoras) nunca são utilizadas em 40\% e 60\% dos casos, respectivamente (Tabela 15).

Para a coordenação específica de diferentes departamentos recorre-se de maneira contínua, também em todos os casos, ao contacto directo e informal. Em 60\% dos casos encontramos também a utilização, quer frequente, quer contínua, de grupos interdepartamentais temporários. Quando estes são permanentes então a sua utilização é menos frequente. A utilização de posições de ligação e de integração é muito pouco frequente, o que certamente é explicado pela reduzida dimensão das empresas analisadas (Tabela 16). 
TABELA 15

Mecanismos de coordenação geral

\begin{tabular}{|c|c|c|c|c|}
\hline \multirow[t]{2}{*}{ Mecanismos } & \multicolumn{4}{|c|}{ Frequência da comunicação (em percentagem)* } \\
\hline & Nunca & Raramente & Frequentemente & Continuamente \\
\hline Contactos directos e informais & - & - & 20 & 80 \\
\hline Sistema de informação/comunicação & 20 & - & - & 80 \\
\hline Supervisão direcła & - & - & 40 & 60 \\
\hline $\begin{array}{l}\text { Estandardização dos processos } \\
\text { de trabalho }\end{array}$ & 20 & - & - & 80 \\
\hline Estandardização dos resultados & 40 & - & 20 & 40 \\
\hline Estandardização dos conhecimentos & 60 & - & 20 & 20 \\
\hline
\end{tabular}

* Computa-se a percentagem de empresas que utiliza os diferentes mecanismos de coordenação geral segundo os diferentes níveis de frequência.

Fonte: inquérito por questionário.

Os resultados obtidos relativamente à coordenação geral e interdepartamental são totalmente consistentes com os obtidos em relação à comunicação interna (ver secção 2).

Quando analisada a flexibilidade organizacional das empresas em estudo observamos que, em $80 \%$ dos casos, o bom funcionamento delas deve-se à definição mais ou menos flexível das responsabilidades e dos procedimentos.

Observamos também que muitas das empresas analisadas realizam esforços pela melhoria contínua (Tabela 17). Na maioria dos casos, os esforços estão focados na melhoria da satisfação dos clientes. Aliás, todas as empresas estudadas declararam desenvolver esforços nesse sentido. A melhoria da criatividade e da estratégia também são assuntos que têm atraído grandes esforços. Isto é natural se considerarmos que a maioria das empresas analisadas declararam ter uma estratégia activa de inovação. Ainda, $60 \%$ das empresas realizam muitos esforços para melhorar aspectos como a comunicação interna, a cultura, a delegação, a descentralização do processo de tomada de decisões, a flexibilidade organizacional e o trabalho em equipa. Convém chamar a atenção para um resultado interessante: a melhoria da comunicação externa requer o esforço de menos empresas que a melhoria da comunicação interna, 
TABELA 16

Mecanismos de coordenação interdepartamental

\begin{tabular}{|c|c|c|c|c|}
\hline \multirow[t]{2}{*}{ Mecanismos } & \multicolumn{4}{|c|}{ Frequência da comunicação (em percentagem)* } \\
\hline & Nunca & Raramente & Frequentemente & Continuamente \\
\hline Contactos directos e informais & - & - & - & 100 \\
\hline Posições de ligação & 80 & - & 20 & - \\
\hline Grupos interdepartamentais temporários & 20 & 20 & 20 & 40 \\
\hline Grupos interdepartamentais permanentes & 40 & 20 & - & 40 \\
\hline Posições de integração & 80 & - & 20 & - \\
\hline
\end{tabular}

* Computa-se a percentagem de empresas que utiliza os diferentes mecanismos de coordenação interdepartamental segundo os diferentes níveis de frequência.

Fonte: inquérito por questionário.

quando vimos que a primeira precisa muito mais que a segunda de melhoramentos, nomeadamente ao nível de comunicação com os centros de produção de conhecimentos (ver secção 2).

Finalmente, observamos que todas as empresas analisadas implementaram inovações organizacionais durante os últimos três anos. Todos os gestores inquiridos reportaram mudanças radicais nas suas empresas, consubstanciadas na introdução de novos sistemas para organizar os processos de trabalho num ambiente de técnicas avançadas de produção. Igualmente, a maioria das empresas experimentaram mudanças significativas nas relações interpessoais e nos processos resultantes das adaptações organizacionais associadas à introdução de novas tecnologias. As mudanças organizacionais também incluíram inovações incrementais, tais como pequenas adaptaçôes derivadas das transformaçôes da envolvente e dos recursos da empresa e a redefinição da estrutura organizacional e a introdução de novos departamentos, embora sem mudanças significativas nas relações interpessoais e nos processos de trabalho. Se todas as funções relacionadas com o processo de inovação têm sido continuamente reorganizadas, a área de produção parece, em termos relativos, a que tem sido objecto de mais inovações organizacionais.

Em resumo, todas as empresas mantêm estruturas organizacionais planas que combinam maioritariamente o critério funcional de departamentalização 
com a departamentalização por produtos ou por clientes. A coordenação, quer geral, quer interdepartamental, apoia-se basicamente no contacto directo de natureza informal. Trata-se de estruturas flexíveis onde o funcionamento é garantido pela definição flexível das responsabilidades e dos procedimentos e onde são introduzidos constantes aperfeiçoamentos, especialmente para melhorar a satisfação dos clientes. Também são introduzidas inovaçôes organizacionais, quer radicais quer incrementais, ligadas à implementação de novas tecnologias e que maioritariamente afectaram a área de produção.

\section{Conclusão}

Foi realizado o estudo aprofundado de cinco PMEs inovadoras localizadas na área da Grande Lisboa. Todas elas são fornecedores especializados que desenvolvem as suas actividades nos sectores do fabrico de equipamento e maquinaria ou do fabrico de maquinaria eléctrica e aparelhagem.

Todas as empresas analisadas começaram como empresas privadas, sem separação entre a propriedade e o controlo. Recentemente, duas destas empresas foram vendidas a grandes companhias, com o intuito de "dotar dum esqueleto a sua cabeça”, passando assim a serem subsidiárias de grandes empresas portuguesas. Além disso, a maioria das empresas estudadas tem uma intensidade em I\&DE média/alta, pelo que podemos concluir que estão razoavelmente empenhadas na inovação.

No que diz respeito aos canais de comunicação, observamos que a nível interno são mais fluídos que a nível externo. A comunicação interna é de natureza informal e frequência contínua. Acontece normalmente entre todas as áreas funcionais da empresa e em todas as direcçóes possíveis. A nível externo, a comunicação é basicamente estabelecida com os clientes e os fornecedores. As relações com as universidades e com instituições de investigação (públicas e privadas) são muito raras. A comunicação com concorrentes e com as agências governamentais é quase inexistente. Constatou-se também que a comunicação externa é mais formalizada que a comunicação interna.

No que diz respeito às relações com os clientes vimos que são principalmente estabelecidas no início do processo de inovação para a análise das suas necessidades, e após o lançamento das inovações para obter o feedback dos 
utilizadores. Refira-se que o envolvimento dos clientes (nomeadamente dos clientes potenciais) nas fases intermédias do processo de inovação é raro.

O apoio explícito da gestão cimeira à inovação tecnológica foi analisado através de vários elementos como a cultura corporativa, a estratégia e o estilo de gestão. A cultura corporativa predominante é um misto das culturas paternalista, afirmativa, integrativa e participativa. As empresas assumem responsabilidades pelo bem-estar dos seus trabalhadores. A política de admissões apoia-se no conhecimento pessoal dos candidatos, embora também sejam analisados os currículos; os objectivos são definidos pelos gestores cimeiros e comunicados a toda a organização. As relações informais desempenham um papel-chave na detecção e resolução de problemas, bem como na recolha de ideias. Trata-se de empresas em que existe uma "cultura de proximidade" entre as pessoas, apoiada por estruturas organizacionais planas que facilitam a comunicação informal e contínua. A gestão cimeira centraliza a tomada de decisões, embora exista uma importante partilha de ideias e os gestores se mostrem disponíveis para os esclarecimentos necessários em relação às decisóes tomadas. A delegação de funções de gestão nos empregados é nula, embora a maioria dos gestores inquiridos se declarem a seu favor. Finalmente, observamos que quase todas as empresas estudadas mantêm uma estratégia activa de inovação, apoiada por umas aptidôes para a gestão tais como a capacidade para utilizar informação, a capacidade para trabalhar em situações ambíguas e, portanto, arriscadas, a cooperação, a liderança e a eficiência.

No que respeita aos recursos humanos, encontramos uma barreira à inovação: a falta de recursos humanos qualificados. Isto provavelmente é explicado pelo facto dos conhecimentos pessoais terem prioridade sobre as qualificações no momento da selecção dos recursos humanos. Esta barreira é agravada pela baixa participação em cursos de formação contínua. Contudo, conseguimos encontrar, com maior ou menor frequência, todos os indivíduos-chave para o processo de inovação. Os indivíduos mais frequentemente encontrados nas empresas analisadas são o sponsor, o inovador do negócio e o inventor. Isto é, combina-se a visão estratégica com a visão comercial e com a visão tecnológica do processo de inovação.

Finalmente, em relação à estrutura organizacional, observamos que todas as empresas mantêm estruturas planas que quase sempre combinam o crité- 
rio funcional de departamentalização com a departamentalização por produtos ou por clientes e, assim, ultrapassam as barreiras que o critério funcional oferece ao bom desenvolvimento dos processos de inovação. A coordenação geral e interdepartamental é basicamente garantida pelo contacto directo de natureza informal embora às vezes sejam utilizados também outros mecanismos. Tratase de estruturas onde são introduzidos constantes aperfeiçoamentos, especialmente para melhorar a satisfação dos clientes. Também são introduzidas inovações organizacionais, quer radicais, quer incrementais, ligadas à implementação de novas tecnologias.

Em conclusão, após a análise pormenorizada dos diferentes factores de gestão determinantes do sucesso da inovação tecnológica, conseguimos detectar duas grandes barreiras à inovação. Por um lado, detectamos uma grande falta de recursos humanos qualificados agravada pelo desinteresse na melhoria contínua da sua formação. Esta lacuna não é preenchida pelo recurso ao conhecimento externo pois, por outro lado, observamos uma importante omissão na comunicação externa com os agentes geradores de conhecimento (universidades e institutos de investigação). Estas duas barreiras afectam outros aspectos que também deveriam ser melhorados como a delegação de funções de gestão e a descentralização da tomada de decisões, unidas a uma transição para culturas corporativas mais participativas e, portanto, favorecedoras da inovação. 


\section{Referências bibliográficas}

Amabile, T., "Motivating Creativity in Organisations: On doing what you love and loving what you do", in California Management Review, v.40, p.39-58, 1997.

Allen, T.J.; Piepmeir, J.; Cooney, S., "The International Technological Gatekeeper”, in Technology Review, 73, 1971.

Assis, J.A.B., External Linkages, Innovation and the Small and Medium Sized Enterprise: The Role and Effectiveness of Public Technology Policy in Portugal, tese de doutorado não publicada. Falmer (Reino Unido): Science Policy Research Unit (SPRU), University of Sussex, 1996.

Barañano, A.M., La empresa española innovadora y los programas RACE, ESPRIT y EUREKA: Un enfoque organizativo, tese de doutorado não publicada, Madri: Universidad Autónoma de Madrid, 1994.

, "The non technological side of technological innovation: state of the art and guidelines for further empirical research", Int. J. Entrepreneurship and Innovation Management, 3 (1 e 2), p.107-125, 2003.

Barlow, J.; Moller, C., Una queja es un regalo: Cómo utilizar la opinión de los clientes para la mejora continua, Madri: Gestión 2000, 2004.

Burns, T., "Mechanistic and Organismic Structures", in Pugh, D.S. (org.), Organization Theory, Londres: Penguin, 1990.

Burns, T.; Stalker, G.M., The Management of Innovation, $3^{\mathrm{a}}$ ed., Oxford: Oxford University Press, 1994.

Caloghirou, Y.; Kastelli, I.; Tsakanikas, A., "Internal capabilities and external knowledge sources: complements or substitutes for innovative performance?” in Technovation 24(1), p.29-39, 2004.

Carter, C.F.; Williams, B.R., Industry and Technical Progress, Oxford: Oxford University Press, 1957.

Castells, M., The Rise of the Network Society (The Informational Age I), Massachusetts: Blackwell, 1996.

Cobbenhaguen, J., Successful Innovation, Cheltenham: Edward Elgar, 2000.

Conceição, P.; Ávila, P., A Inovação em Portugal. II Inquérito Comunitário às Actividades de Inovação, Oeiras: Celta, 2001.

Cooke, P.; Wills, D., "Small Firms, Social Capital and the Enhancement of Business Performance Through Innovation Programmes", in Small Business Economics, 13, p.219-234, 1999. 
Corado Simões, V., Inovação e Gestão em PME, Lisboa: Gabinete de Estudos e Prospectiva Económica do Ministério da Economia, 1997.

Freeman, C., The Economics of Industrial Innovation, Londres: Penguin Modern Economic Texts, 1974.

, The Economics of Industrial Innovation, 2a ed., Londres: Frances Pinter (Publishers), 1982.

Galende, J.; de la Fuente, J.M., "Internal factors determining a firm's innovative behaviour", in Research Policy, 32 (5), p.715-736, 2003.

Galende, J.; Suarez, I., "Los factores determinantes de las inversiones empresariales em I+D”, in Economia Industrial, 319, p.63-76, 1998.

"A resource-based analysis of the factors determining a firm's R\&D activities", in Research Policy 28, p.891-905, 1999.

Grant, R.M., "Towards a Knowledge-Based Theory of the Firm”, in Strategic Management Journal, v.17, número especial de Inverno, p.109-122, 1996.

Gurteen, D., "Knowledge, creativity and innovation", in Journal of Knowledge Management, v.2, p.5-13, 1998.

Hayvaert, C.H., Innovation research and product policy: clinical research in 12 Belgian industrial enterprises. Bélgica: Université Catholique de Louvain, 1973.

Hofstede, Cultures and organizations. Software of the mind, Londres: Harper Collins Business, 1991.

Igel, B.; Islam, N., "Strategies for service and market development of entrepreneurial software designing firms", in Technovation, 21(3), p.157-166, 2001.

IMIT - Institute for Management of Innovation and Technology, International Transfer of Organizational Innovation, EIMS Publication n.45, 1996.

Kaplan, R.; Norton, D., "The Balanced Scorecard: Measures that Drive Performance”, in Harvard Business Review, p.71-79, 1996.

Langrish, J. et al., Wealth from Knowledge, Londres: MacMillan, 1972.

Lenox, M.; King, A., "Prospects for developing absorptive capacity through internal information provision", in Strategic Management Journal 25 (4), p.331-345, 2004.

Lundvall, B.A. (org.), National Systems of Innovation: towards a theory of innovation and interactive learning, Londres: Pinter, 1992.

Martínez-Ros, E.; Salas, V., "Innovación y salarios en la manufactura española”, in Papeles de Economia Española, 81, p.92-103, 1999. 
McAdam, R.; McClelland, J., "Sources of new product ideas and creativity practices in the UK textile industry", in Technovation, v.22, p.113-121, 2002.

Meritum Guidelines for Managing and Reporting on Intangibles (Intellectual Capital Reports), Madri: Fundación Airtel, 2002.

Mintzberg, H., The Structuring of Organizations, Englewood Cliffs: PrenticeHall, 1979.

, Structure in five: Designing Effective Organizations, Englewood Cliffs: Prentice-Hall, 1992.

Myers, S.; Marquis, D.G., Successful Industrial Innovation, Washington: National Science Foundation, 1969.

Nahapiet, J.; Ghoshal, S., "Social capital, intellectual capital and the organizational advantage", in Academy of Management Review, 23(2), p.242-266, 1998.

Nieto, M., "Características dinámicas del proceso de innovación tecnológica en la empresa" in Investigaciones Europeas de Dirección y Economía de la Empresa, 9 (3), p.111-128, 2003.

OECD, Oslo Manual. Paris: OECD, 1997.

Ostroff, F., The Horizontal Organization. Oxford: Oxford University Press, 1999.

Rayney, B.; Barañano, A.M.; Chansarkar, B.; Cuevas, F.; Raut-Roy, U., Priorities for Executive Development (PED) Final Report - LEONARDO DA VINCI projecto no E97200453 EAIII 2.A, 166 p., 2000.

Romijn, H.; Albadalejo, M., "Determinants of innovation capability in small electronics and software firms in southeast England", in Research Policy, 31(7), p.1.053-1.067, 2002.

Rothwell, R., "Innovation in textile machinery: some significant factors in success and failure", in Science Policy Research Unit, Occasional Paper Series n.2, jun., 1976.

Rothwell, R. et al. , “SAPPHO updated: Project SAPPHO phase II", in Research Policy, 3, p.258-291, 1974.

Rothwell, R.; Robertson, A.B., "The role of communications in technological innovation", in Research Policy, 2, p.204-225, 1973.

Sánchez, M.P.; Chaminade, C.; Olea, M., "Management of Intangibles. An attempt to build a theory", in Journal of Intellectual Capital, 1(4), p.312$327,2000$.

Sirilli, G., "New frontiers in the measurement of innovation", in International Conference on Technology Policy and innovation, Monterrey, México: junho, 2003. 
Schock, G., Innovation processes in Dutch industry. Apeldoorn: T.N.O. Industrial Research Organization, 1974.

Spender, J.C., "Making knowledge the basis of a dynamic theory of the firm", in Strategic Management Journal, v.17 (número especial de Inverno), p.45-62, 1996.

Szakasits, G.D., "The adoption of the SAPPHO method in the Hungarian electronics industry", in Research Policy, 3, 1974.

Tidd, J.; Bessant, J.; Pavitt, K., Managing Innovation: integrating technological, market and organizational change, Chichester: John Wiley \& Sons, 1997. ; Managing Innovation. Integrating Technological, Market and Organizational Change, 2a ed., Chichester: John Wiley \& Sons, 2001.

Utterback, J.M.; Allen, T.J.A.; Hollomon, J.H.; Sirbu, Jr., M.A., The process of innovation in five industries in Europe and Japan, Massachusetts: Center for Policy Alternatives, M.I.T., 1975.

Veugelers, R.; Cassiman, B., "Make and buy in innovation strategies: evidence from Belgian manufacturing firms", in Research Policy, v.28, p.63-80, 1999.

Wernerfelt, B., “A Resource-based View of the Firm”, in Strategic Management Journal, 5, p.171-180, 1984.

Womack, J.P.; Jones, D.T.; Roos, D., The Machine that Changed the World, Nova York: Harper Perennial, 1991. 